\title{
Laser Irradiation on Tin Electroplating and Whisker Suppressibility
}

\author{
Makoto HINO $^{{ }^{* 1}}$, Yutaka MITOOKA ${ }^{* 1}$, Koji MURAKAMI ${ }^{* 1}$, Masao TAKAMIZAWA ${ }^{* 2}$ and Teruto KANADANI ${ }^{* 3}$ \\ ${ }^{*}$ Industrial Technology Research Institute of Okayama Prefecture, 5301, Haga, Kita-ku, \\ Okayama-shi, Okayama, 701-1296, Japan \\ E-mail: Makoto_hino@pref.okayama.lg.jp \\ *2 OM Sangyo Co.,Ltd., 3-18-48, Noda, Kita-ku, Okayama-shi, Okayama, 700-0971, Japan \\ *3 Okayama University of Science, 1-1, Ridai-cho, Kita-ku, Okayama-shi, Okayama, 700-0005, \\ Japan
}

\begin{abstract}
Tin electroplating with its excellent solderability and low cost performance is garnering attention as a lead-free technology. However, tin electroplated film is plagued with the issue of whisker formation. In this research, in order to suppress the whisker formation, the effect of laser irradiation on tin electroplated film onto a phosphor bronze substrate was studied by scanning electron microscopy and focused ion beam microscopy. Whiskers and nodules were generated on the surface of the tin electroplated film for a short time after electroplating. However, laser irradiated specimens showed no whiskers as well as nodules. This whisker suppression is attributable to the formation of thinly uniform intermetallic compound layer. Moreover, the solderability of the laser irradiated specimen was superior to that of the reflow specimen. These results demonstrated the effectiveness of laser treatment.

DOI:10.2961/jlmn.2012.02.0010
\end{abstract}

Keywords: tin electroplating, laser processing, whisker, solderability, intermetallic compound

\section{Introduction}

Tin-lead $(\mathrm{Sn}-\mathrm{Pb})$ alloy electrodeposition, because of its excellent solderability and low cost, has been widely utilized for the soldering components such as the connectors in electronic devices, but regulations passed in the EU on hazardous substances have placed strict restrictions on the usage of the lead, creating a demand for the establishment of the lead-free electrodeposition technologies. As such, tin electrodeposition with its excellent solderability and low cost performance, is garnering attention as a lead-free electrodeposition technology. However, the tin electrodeposition is plagued with the issue of the whisker formation shown in Fig. 1, with the whiskers sometimes growing up to several millimeters in length [1,2]. In the electronic devices faced with consumer demand for continued the size reduction, tin whiskers can cause a short circuit. Currently, this is a major obstacle hindering the use of the tin electrodeposition for applications such as the soldering of connectors.

The present authors have conducted a research on the mechanism of whisker growth on tin electroplated films $[3,4]$ and on the behavior of lead in tin-lead films [5]. According to the previous reports [6-10], whiskers generation and growth of are considered to be due to nonuniformity of residual stress caused by copper-tin intermetallic compound $\left(\mathrm{Cu}_{6} \mathrm{Sn}_{5}\right)$ which preferably grows on the grain boundaries of tin.

At the present time, the reflow treatment which makes a film to be the molten state is conventionally conducted after the electroplating for the purpose of preventing the whisker generation and growth [11]. Usually, the heating time of this treatment is over several decade minutes, so there are several problems such as the formation of coppertin intermetallic compound $\left(\mathrm{Cu}_{6} \mathrm{Sn}_{5}\right)$ which reaches on the surface and lowering of the solder wettability by means of the surface oxidation [3].

On the other hand, laser processing, such as surface quenching for the steel, has been widely applied as a highdensity energy supply source [6]. Laser processing has made it possible to treat at narrow area and enables the rapid heating. Therefore, it is possible to suppress the heat effect against the substrate. At the present time there are many kinds of laser with different wavelength. The diode laser, whose wavelength is $0.8-1 \mu \mathrm{m}$, is advantageous for surface modification to the metal as follows. The efficiency of the diode laser is about $50 \%$ and is more excellent than that of other laser. The laser beam is capable of propagation through the optical fiber, and the energy absorption rate of this beam onto metal substrate is higher than that of the $\mathrm{CO}_{2}$ laser.

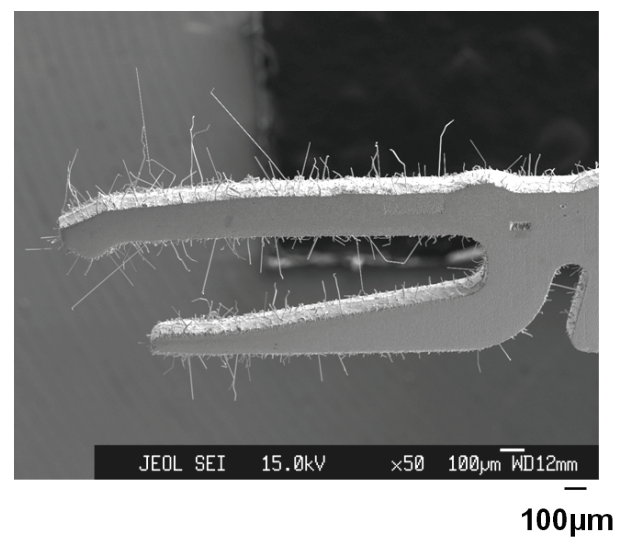

Fig. 1 Whisker growth of tin electroplated film. (Pressurization test by acrylic board for $36 \times 10^{6} \mathrm{~s}$ ) 
Table 2 Bath composition and plating conditions.

\begin{tabular}{cll}
\hline Plating type & \multicolumn{1}{c}{ Sn Plating } & \multicolumn{1}{c}{ Cu Plating } \\
\hline & Tin: $50(\mathrm{~g} / \mathrm{L})$ & $\mathrm{Cu}(\mathrm{CN}): 80(\mathrm{~g} / \mathrm{L})$ \\
Bath composition & Free-acid : 100 $(\mathrm{g} / \mathrm{L})$ & $\mathrm{KCN} \quad: 30(\mathrm{~g} / \mathrm{L})$ \\
& Additives $(\mathrm{amine}): 10 \mathrm{~mL} / \mathrm{L}$ & 10.5 \\
Bath $\mathrm{pH}$ & 1.0 & 0.5 \\
Current density $\left(\mathrm{kA} / \mathrm{m}^{2}\right)$ & 1.0 & 323 \\
Temperature $(\mathrm{K})$ & 295 & 2 \\
Thickness $(\mu \mathrm{m})$ & 3 & \\
\hline
\end{tabular}

Table 1 Laser irradiated conditions.

\begin{tabular}{cc}
\hline Parameter & Value \\
\hline Wavelength & $808 \mathrm{~nm}$ \\
Focusing distance & $100 \mathrm{~mm}$ \\
Exposure mode & pulse \\
Defocusing distance & $20 \mathrm{~mm}$ \\
Irradiated beam diameter & $10 \mathrm{~mm}$ \\
Exposure angle & $90 \mathrm{deg}$ \\
Laser power & $400,700 \mathrm{~W}$ \\
Irradiated speed & $100,200 \mathrm{~mm} / \mathrm{s}$ \\
\hline
\end{tabular}

In this investigation, for the purpose of the control of whisker generation and growth, the diode laser for surface modification was applied to the melting of the tin film, and the relationships between the laser irradiated condition and the suppressibility of the whisker generation and growth were examined.

\section{Experimental procedure}

The phosphor bronze rolled sheet processed into the connector (Thickness: $0.2 \mu \mathrm{m}$, JIS C-5191) shown in Fig.2 was employed for the substrate in this study. Electroplating of tin and copper on the substrate was carried out under the conditions shown in Table 1. The specimens first underwent pretreatment by alkali cleaning and pickling. The copper electroplating was first done followed by the tin electroplating. They were then subjected to constant current electrolysis.

The laser equipment used in this investigation was a diode laser (Laser Line Co. Ltd., LDF600-1000). Laser irradiated conditions is shown in Table 2. The nitrogen gas was sprayed in order to prevent the oxidation. For comparison, the reflow treatment $(533 \mathrm{~K}, 0.3 \mathrm{ks})$ using the warm wind heating furnace under the nitrogen atmosphere was also used to prepare the specimens.

A field emission scanning electron microscope (FESEM) was used for observation of the whisker generation and growth for each specimen for 3.6 Ms after the plating in an ambient atmosphere. A focused ion beam (FIB) was used for observation of copper-tin intermetallic compounds which developed at the interface between plated films and substrate. A microfocus X-ray diffractometer with twodimensional detector was used for measuring residual

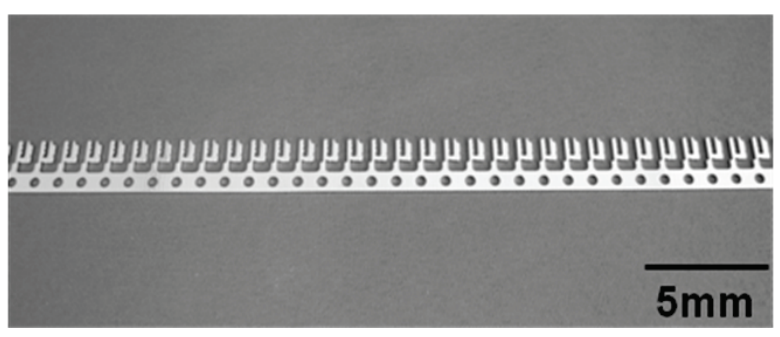

Fig. 2 Appearance of connector.

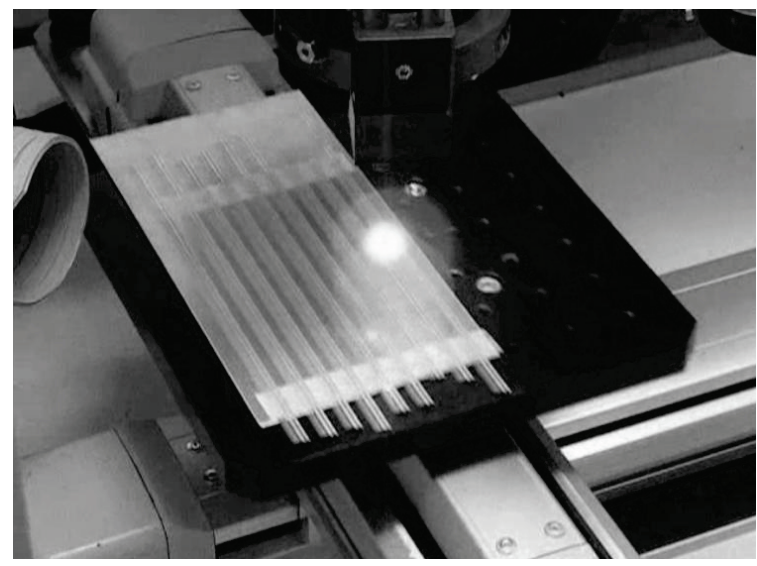

Fig. 3 Appearance of laser irradiation for the specimens.

stress of each specimen. Moreover, solderability was measured by the wetting balance method.

\section{Experimental results and discussion}

\subsection{Laser irradiation}

Figure 3 shows the appearance of laser irradiation for the electroplated specimens. The white light emission was confirmed at the laser irradiated point on each specimen. At that time, the intensity of the white light emission increased with increasing laser power from $400 \mathrm{~W}$ to $700 \mathrm{~W}$. However, there was no difference of this appearance during laser irradiation under this laser irradiated condition, and the distortion of each specimen was then slight after laser irradiation. This may be caused by the rapid heating and cooling of laser processing. Moreover, as the laser power increased over $700 \mathrm{~W}$, the melt-down of the substrate took place.

Figure 4 shows the microscopic views of the specimens after the reflow treatment and the laser irradiation. The 

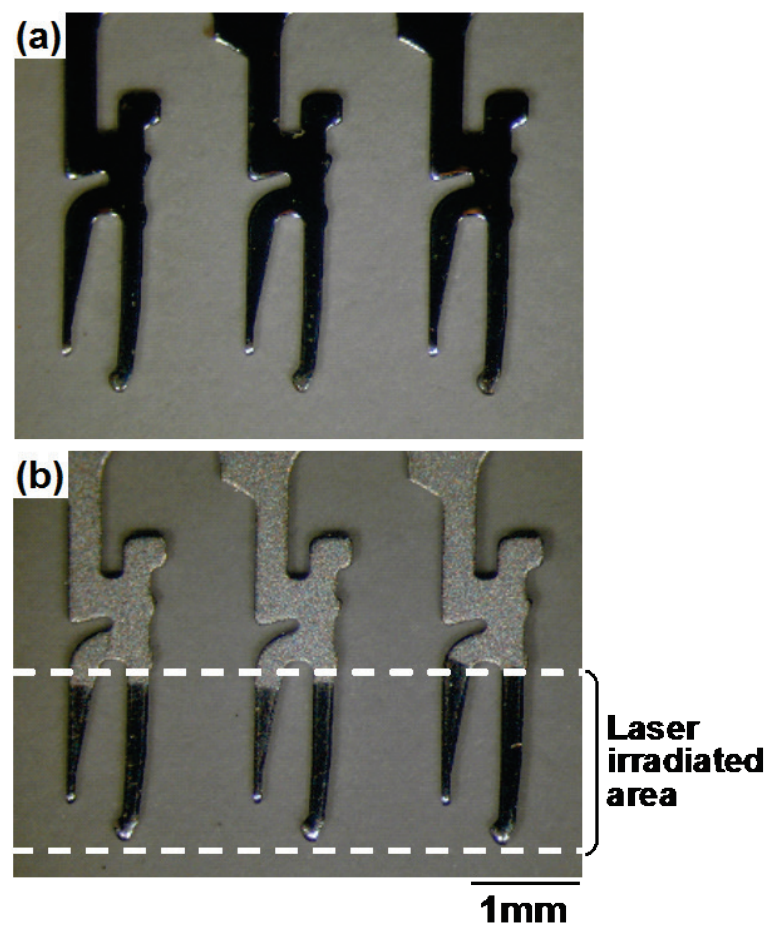

Fig. 4 Microscopic views of the specimens after various heat treatment.

(a) Reflow treatment (b) Laser irradiation

surface appearance of the as-plated specimen without laser irradiated area shown in Fig.4 (a) was the silver albedo with the slight luster. However, that with the reflow treatment became luster in terms of melting a plated tin film shown in Fig.4 (b). Laser irradiated surface appearance (Laser power: 700W, Irradiated speed: $200 \mathrm{~mm} / \mathrm{s}$ ) was also luster and the same as that of the reflow treatment.

Figure 5 shows the FE-SEM images of the specimens after the laser irradiation and the reflow treatment. The surface morphology of the as-plated specimen (Fig.5 (c)) was fine grain and the surface roughness $\mathrm{Ra}$ was approximately $1 \mu \mathrm{m}$, which corresponds to the grain size of tin. The laser irradiated and reflow treated surfaces became smooth, which completely lost the initial surface state on the asplated specimen, respectively. These results suggest that a tin plated film has completely molten with this laser irradiation.

In this way, laser treatment has made it possible to melt a tin film in the extreme time by the high-density energy of the laser. Furthermore, the partial melting which can not correspond in the reflow treatment becomes feasible as shown in Fig.4 (b).

\subsection{Effect of laser irradiation on the whisker suppress- ibility}

Figure 6 shows the FE-SEM images of electroplated films with each treatment for 3.6 Ms in an ambient atmosphere. In the as-plated specimen, growth of whiskers over $50 \mu \mathrm{m}$ in length was observed and nodular hillocks were also found in others as shown in Fig.6 (a). On the other hand, no whiskers were found in the laser irradiated specimen (Laser power: 700W, Irradiated speed: $200 \mathrm{~mm} / \mathrm{s}$ ) as well as the reflow treated specimen for the same duration as shown in Fig.6 (b), (c).
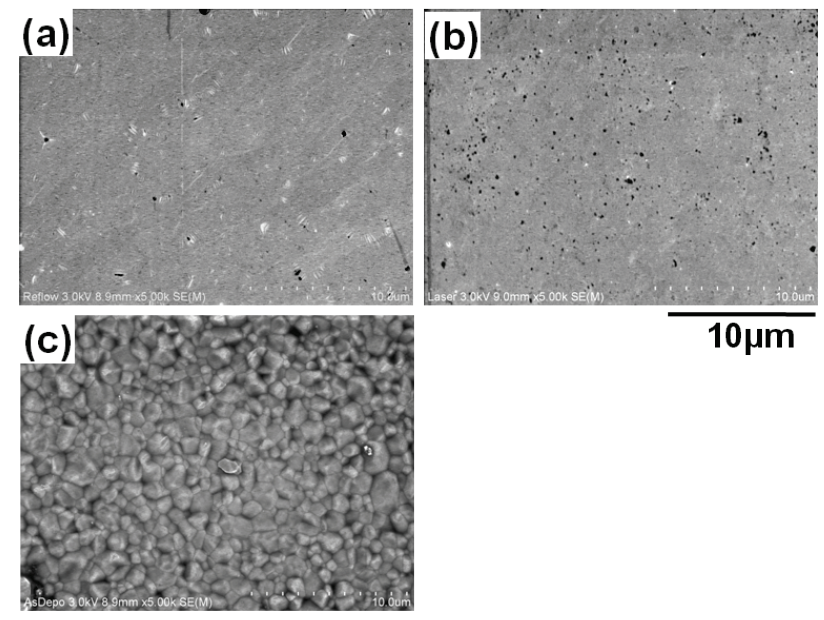

$10 \mu \mathrm{m}$

Fig. 5 FE-SEM images of the specimens after various heat treatment.

(a) Reflow treatment (b) Laser irradiation (c) As plated
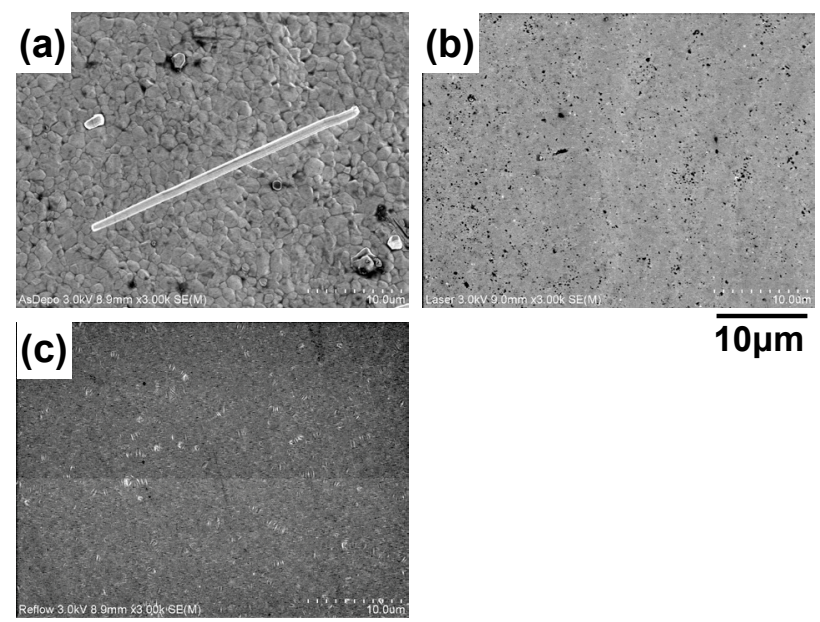

$\overline{10 \mu \mathrm{m}}$

Fig. 6 FE-SEM images of tin deposits with various treatment for 3.6 Ms in an ambient atmosphere.

(a) As plated (b) Laser irradiation (c) Reflow treatment

In this way, it was found that these treatments which make a tin film to be the molten state were quite effective after the electroplating for the purpose of preventing the whisker generation and growth. According to $\mathrm{Tu}$ [7], the factor of the whisker suppression by fusion of a tin film is attributable to the stress relieving of a tin film and the prevention of $\mathrm{Cu}$ diffusion to the tin film, depending on the formation of $\mathrm{Cu}_{3} \mathrm{Sn}$ compound layer.

Figure 7 shows the residual stress in the tin film obtained by X-ray diffraction. In the case of the as-plated specimen, the residual stress of the tin film was compressive immediately after electroplating, as previously reported [2]. This value then increased with increasing the time, and became finally -15 MPa. This compressive stress may be driving force of the whisker generation and growth, as shown in Fig.6 (a) [8].

On the other hand, the laser-irradiated specimen (Laser power: $700 \mathrm{~W}$, Irradiated speed: $200 \mathrm{~mm} / \mathrm{s}$ ) showed the tensile residual stress of $2 \mathrm{MPa}$ immediately after laser irradiation, and then the residual stress became slightly the compression. Finally, the residual stress was $2 \mathrm{MPa}$ in tension. 


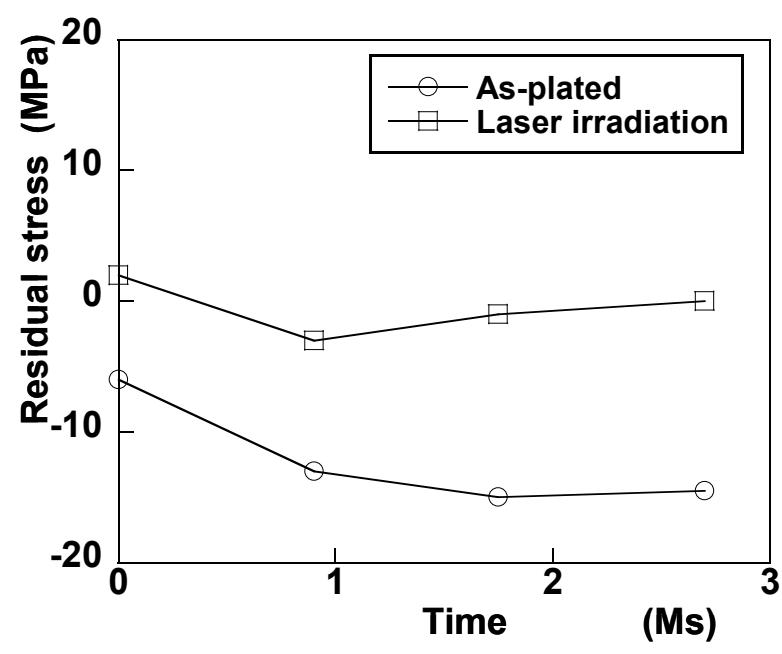

Fig. 7 Residual stress of tin film with and without laser irradiation obtained by X-ray diffraction.

The reflow treated specimen was also same tensile residual stress. The initial compressive residual stress in the asplated specimen is canceled by the laser irradiation as well as the reflow treated specimen, since tin atoms are arranged in elastically state during solidification. As shown in Fig.6 (b), (c), the whisker suppression by the laser irradiation and the reflow treatment seems to be attributable to the tensile residual stress.

Figure 8 shows the results of the zero-cross time measured by the wetting balance method. The zero-cross time of the as-plated film was the lowest value and this result indicated that the solder wettability of as-plated film was most excellent. Therefore, it was proven that the thermal history with melting a film such as the reflow treatment and laser irradiation caused the solder wettability adverse effect. While the tin films with the reflow treatment and the laser irradiation had equally molten, the solder wettability of the laser irradiated film was excellent. These results seem to be attributable to the suppression of the surface oxidation by the rapid heating of the laser processing.

In this way, the laser processing is also excellent in not only the whisker suppression but also the solder wettability of tin film.

Figure 9 shows the cross-sectional scanning ion micrograph of the tin and copper deposits and substrate for 3.6 $\mathrm{Ms}$ in an ambient atmosphere. Copper-tin intermetallic compounds (IMC) were nonuniformly formed in a tin film. This nonuniform formation of copper-tin intermetallic compounds made the compressive stress arise, as shown in Fig.8. The whisker then generated by means of this compressive stress.

Figure 10 shows the cross-sectional scanning ion micrograph of the tin and copper deposits and substrate after the reflow treatment. The diffusion layer which consists in the copper-tin intermetallic compounds had reached the surface, and then the tin slightly remained in a tin film. Heating duration of the reflow treatment is $0.3 \mathrm{ks}$. The copper atoms seem to diffuse into most of the tin film by means of the melting state for $0.3 \mathrm{ks}$. According to the report [5], the copper-tin intermetallic compounds which reached the tin file surface are made to lower the solder

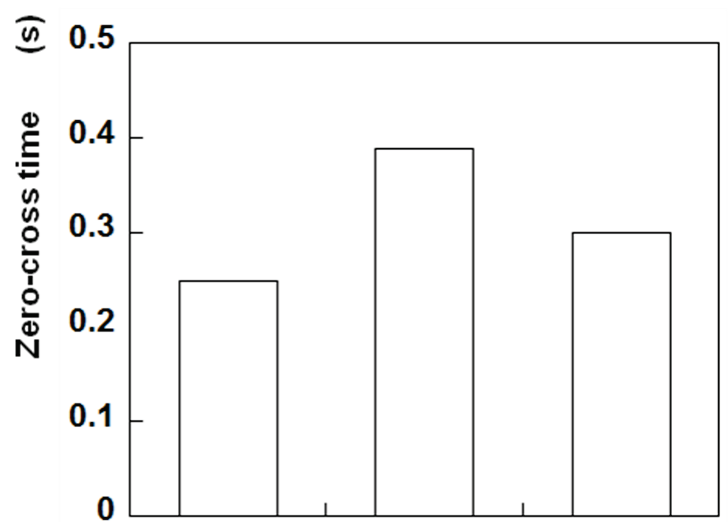

(a)

(b)

(c)

Fig. 8 Zero-cross time of tin deposits with various treatment. (a) As-plated (b) Reflow treatment (c) Laser irradiation (Laser power: 700W, Irradiated speed: 200)

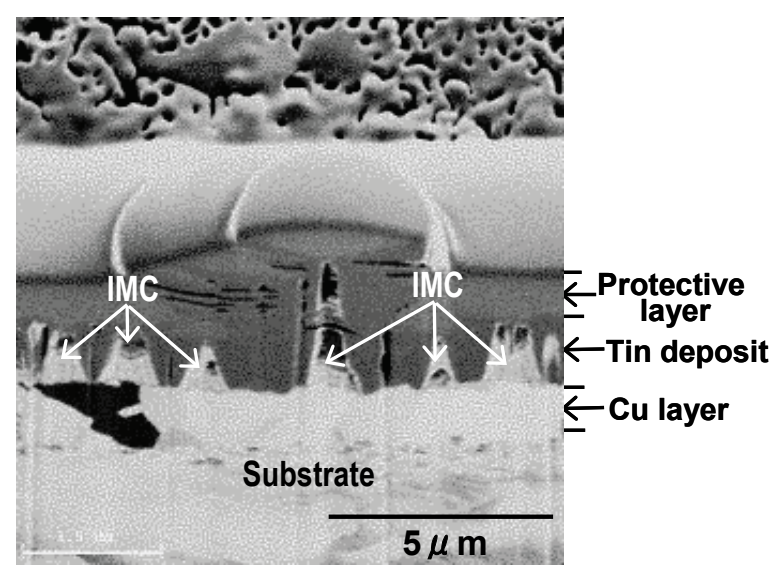

Fig. 9 Cross-sectional scanning ion image of tin deposit for 3.6 Ms in an ambient atmosphere.

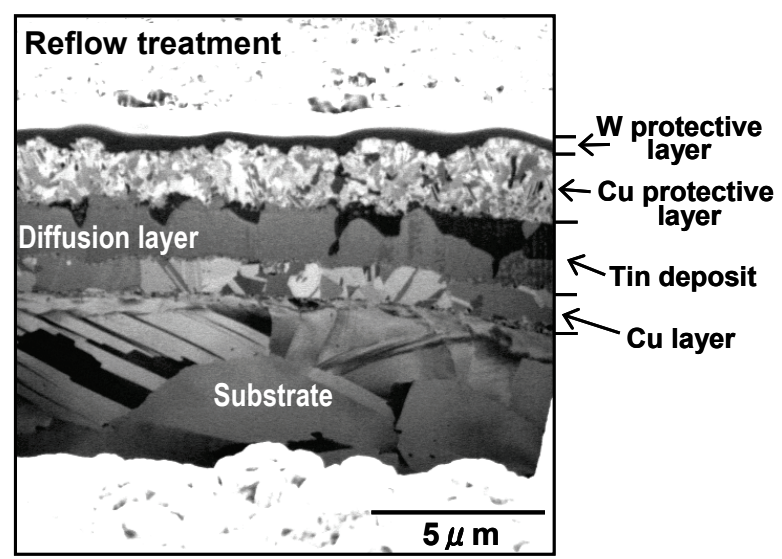

Fig. 10 Cross-sectional scanning ion image of tin deposit after reflow treatment.

wettability. This result is in good agreement with the solder wettability of the reflow treated film shown in Fig. 8.

Figure 11 shows the cross-sectional scanning ion micrographs of the tin and copper deposits and substrate after the laser irradiation. On laser irradiated specimen (Laser power: $400 \mathrm{~W}$, Irradiated speed: $100 \mathrm{~mm} / \mathrm{s}$ ), the diffusion layer which consists in copper-tin intermetallic compounds 


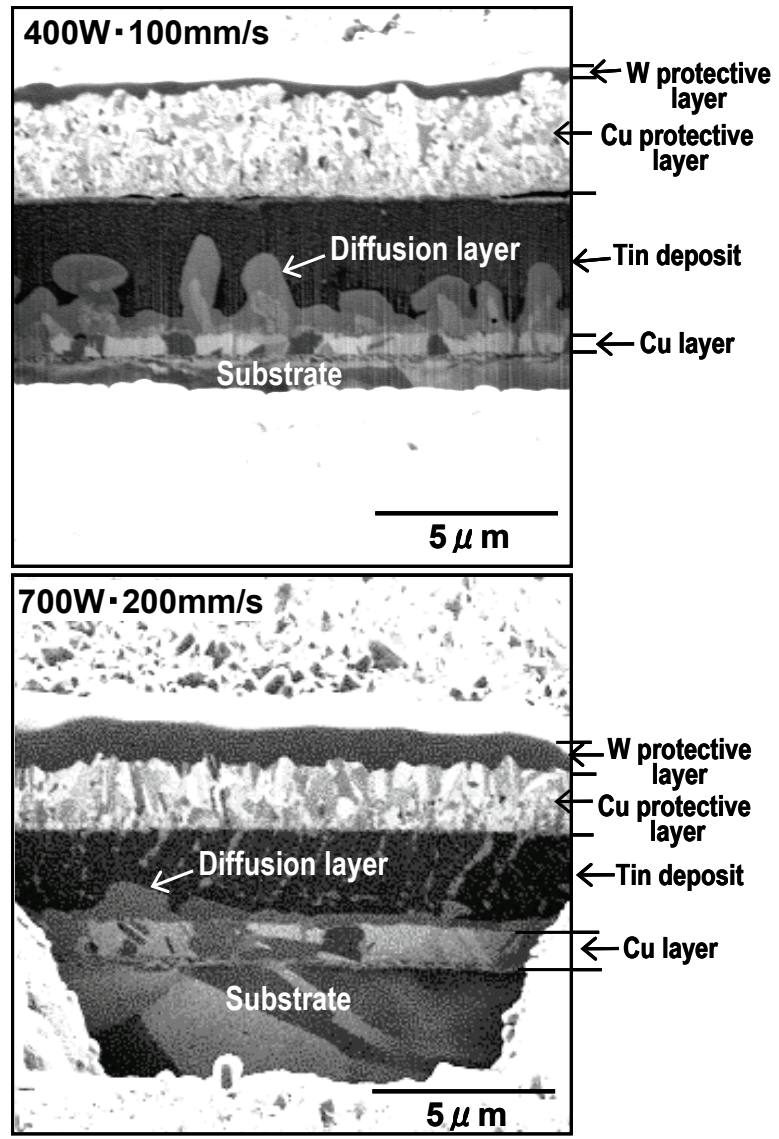

Fig. 11 Cross-sectional scanning ion image of tin deposit after laser irradiation under various conditions.

was nonuniformly formed in a tin film. On the other hand, the diffusion layer of the specimen with laser irradiation (Laser power: $700 \mathrm{~W}$, Irradiated speed: $200 \mathrm{~mm} / \mathrm{s}$ ) was uniformly formed along the copper layer in a tin film. However, both diffusion layers have not reached the tin film surface, and then the tin remained in the surface side. It seems that this remained tin suppresses the lowering of the solder wettability. In this way, it was found that a difference of the laser irradiated condition varied much with the diffusion layer.

On the diffusion, there are intracrystalline diffusion and grain boundary diffusion. In the low-temperature region, the grain boundary diffusion progresses further than the intracrystalline diffusion. As shown in Fig. 9, the diffusion layer which consists in the copper-tin intermetallic compounds is formed along grain boundary.

On the other hand, in the high-temperature region, there is little difference between the intracrystalline diffusion and the grain boundary diffusion. As shown in Fig. 11, the diffusion layer with laser irradiation (Laser power: 700W, Irradiated speed: $200 \mathrm{~mm} / \mathrm{s}$ ) was uniformly formed along the copper layer in a tin film. The rapid heating by laser irradiation brings about this uniform diffusion layer. In the case of laser irradiated condition (Laser power: $400 \mathrm{~W}$, Irradiated speed: $100 \mathrm{~mm} / \mathrm{s}$ ), the nonuniform diffusion layer was formed. The grain boundary diffusion will progress, because the heating duration becomes longer.

Therefore these results indicate that the laser processing enables microstructure control.

\section{Summary}

In this paper, the laser for surface modification was applied to the melting of the tin film, and the relationships between the laser irradiated condition and the suppressibility of the whisker generation and growth were examined. The results are summarized as follows.

(1) Whiskers and nodules were generated on the surface of the tin electroplated film for a short time after electroplating. However, laser irradiated specimens whose tin film were molten showed no whiskers as well as nodules. In addition, the reflow treatment also indicated the suppressibility of the whisker generation and growth. The solder wettability of the laser irradiated film was more excellent than that of the reflow treated film. This solderability is attributable to the depression of the oxidation.

(2) Laser processing has made it possible to melt a tin film in the extreme time by the high-density energy of the laser, and then the partial melting which can not correspond in the reflow treatment becomes feasible. Therefore, the productivity of the laser processing is more excellent than that of the reflow treatment for the tin whisker suppression. Furthermore, the laser processing enables microstructure control.

\section{References}

[1] NASA Goddard Tin (and other Metal) Whisker WWW Site http://nepp.nasa.gov/whisker

[2] JEITA namari-free-ka-katsudou-seika-houkokukai 2009: Japan Electronics and Information Technology Industries Association, (electronics packaging standardization committee, 2009) 59.

[3] K. Murakami, M. Hino, M. Takamizawa and K. Nakai: Mater. Trans., 49, (2008) 2829.

[4] K. Murakami, M. Okano, M. Hino, M. Takamizawa and K. Nakai: J. Jpn. Inst. Metals, 72, (2008) 648. (in Japanese)

[5] M. Takamizawa, T. Naka, M. Hino, K. Murakami and K. Nakai: J. Jpn. Inst. Metals, 72, (2008) 229. (in Japanese)

[6] R.Kawanaka, Y.Fujiwara, K.Tsuji, S.Ito and Y.Ihara;Namari Uisuka seicho purosesunokaimeitotaisaku, (R\&D Planning,2006) p.141. (in Japanese)

[7] B. -Z. Lee and D. N. Lee: Acta Mater., 46, (1998) 3701.

[8] G. T. Galyon: IEEE Trans. Electron. Pack. Manuf., 28, (2005) 94.

[9] T.Kato, H. Akahoshi, M.Nakamura, T. Hashimoto and A. Nishimura: IEEE Trans. Electron. Pack. Manuf., 30, (2007) 258.

[10] K. Tsuji: J. Surf. Fin. Soc. Jpn. 58, (2007) 406.

[11] T.Kato, H. Akahoshi, M.Nakamura, T. Iwasaki, T. Hashimoto and A. Nishimura: IEEE Trans. Electron. Pack. Manuf., 33, (2010) 165

[12] M.Hino, M.Hiramatsu, K.Akiyama, H.Kawasaki, M.Tsujikawa and M.Kawamoto: Mate. and Manufacturing Processes, 11, (1997) 37.

[13] K.N.Tu;Acta Met.,21, (1973) 347.

[14] K. Murakami, G. Miyamoto, M. Okano, M. Hino, M. Takamizawa and K. Nakai: J. Surface Finish. Soc. Jpn., 59, (2008) 913.

(Received: May 17,2011, Accepted: April 05, 2012) 